\title{
Produção de proteína microbiana e derivados de purinas em vacas
}

\author{
José Alípio Faleiro Neto', Elizângela Mirian Moreira'2, Ronaldo Braga Reis ${ }^{3}$, Ivan \\ Barbosa Machado Sampaio ${ }^{4}$, Helton Mattana Saturnino ${ }^{5}$, Tiago Castro dos Reis ${ }^{6}$, Jacob \\ Alan Reed ${ }^{7}$ \\ ${ }^{1}$ Doutor em Nutrição e Produção Animal FMVZ/USP. Endereço para correspondência: Av. Pádua Dias 11, Dep. Zootecnia, \\ Cep: 13418900,Piracicaba, São Paulo,e-mail: faleironeto@usp.com.br \\ ${ }^{2}$ Doutoranda em Nutrição e Produção Animal FMVZ/USP, e-mail: elizangelavet2005@gmail.com \\ ${ }^{3}$ Professor adjunto DZO-EV-UFMG.e-mail: rbreis@vet.ufmg.br \\ ${ }^{4}$ Professor Titular DZO-EV-UFMG.e-mail: Ivan@vet.ufmg.br \\ ${ }^{5}$ Professor adjunto DZO-EV-UFMG.e-mail: helton@vet.ufmg.br \\ ${ }^{6}$ Tiago Castro dos Reis DZO-EV-UFMG.E-mail: tiagovetufmg@yahoo.com.br \\ ${ }^{7}$ Department of Animal Science. Oklahoma State University e-mail: Jacob.reed@okstate.edu
}

\begin{abstract}
RESUMO. Sete vacas Holandesas vs. Zebus com peso médio de $583 \mathrm{~kg}$, com 45 dias de lactação, produção média diária de $25 \mathrm{~kg}$ de leite e mantidas em tie stall foram distribuídas em delineamento tipo blocos incompletos balanceados com os seguintes tratamentos: ureia 0,$3 ; 0,6$ e $0,9 \%$ ou Optgen $\mathrm{II}^{\circledR}$ nos mesmos níveis e um controle. Não houve efeito para as seguintes variáveis: VUR (L/dia), Acu (mmol/dia), CRE (mmol/dia), Pur Totais (mmol/dia), Pabs (mmol/dia), Nmic (g/dia) e Pmic (g/dia). Houve efeito apenas para concentração de alantoína (mmol/dia).
\end{abstract}

Palavras chave: Ácido úrico, alantoína, proteína microbiana, ureia

\section{Microbial protein production and purine derivatives in cows}

\begin{abstract}
Seven multiparous Holsteins $v s$. Zebus cows with $45 \pm 12$ days in milk and $25 \mathrm{~kg}$ of milk per day were used. The cows were distributed in seven treatments in a balanced incomplete block design. All the cows were in a tie stall barn receiving diets based on fresh chopped sugarcane with increasing levels of urea or OptigenII ${ }^{\circledR}: 0.3 \%$, $0.6 \%, 0.9 \%$ and a control group without urea. There was no effect $(\mathrm{P}>0.05)$ for the following variables: VUR (L/day), Acu (mmol/day), CRE (mmol/day), Total Pur (mmol/day), Pabs (mmol/day), Nmic (g/day) and PMIC (g/day). It was effect $(\mathrm{P}<0.05)$ only on allantois concentration (mmol/day).
\end{abstract}

Keywords: Uric acid, allantoin, microbial protein, urea

\section{Introdução}

A proteína metabolizável (PM) no intestino de ruminantes é representada pelo total de aminoácidos provenientes da digestão intestinal da proteína microbiana produzida no rúmen, proteína não degradada no rúmen (PNDR) de origem alimentar e da proteína endógena (Berchielli et al., 2011).

A proteína microbiana (Pmic) normalmente é a principal fonte de proteína utilizada por ruminantes na maioria das situações produtivas, podendo representar ao redor de 45 a $55 \%$ da PM no intestino de vacas leiteiras de alta produção,
55 a $65 \%$ para bovinos de corte confinados em dietas de alto concentrado (ricas em energia) e, mais de $65 \%$ em bovinos mantidos exclusivamente em pastagens (NRC, 2000, NRC, 2001). Neste contexto, qualquer sistema de produção e nutrição, só terá sucesso quando da otimização da produção de Pmic.

A cana de açúcar é utilizada desde há muito tempo na alimentação de ruminantes. Devido a sua facilidade de cultivo, execução da colheita na época de estiagem do ano e sua alta produção por área, este volumoso torna-se cada vez mais atraente para produtores e pesquisadores. Sendo 
um volumoso pobre em proteína, a adição de ureia, visa corrigir a deficiência deste nutriente (Costa et al., 2011, Costa et al., 2005, Maeda et al., 2011).

O fluxo de nitrogênio microbiano para o duodeno pode ser estimado a partir da excreção urinária de derivados de purinas (principalmente alantoína e ácido úrico) em que, a quantidade de ácido nucléico microbiano e a síntese microbiana ruminal são altamente correlacionadas a excreções urinárias de derivados de purina (Moscardini et al., 1998). Nesse contexto, mostra-se a utilidade dos derivados de purina urinários como potenciais ferramenta para detecção da síntese de proteína microbiana ruminal com a mesma eficiência do método de medição do fluxo duodenal da técnica de dois indicadores.

Existem vários métodos para estimativas da produção de proteína microbiana como: utilização de marcadores internos, bases purinas e ácido 2,6 diaminopimélico (DAPA) e, externos como $35 \mathrm{~S}$ e $15 \mathrm{~N}$. Devido a estes métodos exigirem animais canulados e também exigir a determinação do fluxo de matéria seca no abomaso, o desenvolvimento de técnicas não invasivas para estimar a produção microbiana tem sido bastante utilizado (Oliveira et al., 2001). $\mathrm{O}$ uso da excreção de derivados de purinas para determinar a produção de proteína microbiana foi citado por Chen \& Ørskov (2004); porém, maiores progressos para esta metodologia foram realizados.

A xantina, hipoxantina, ácido úrico $\mathrm{e}$ alantoína são denominadas como derivados de purinas (DP), sendo estes, produtos do catabolismo das purinas excretadas na urina de ruminantes onde, a alantoína está presente em maior quantidade, originando-se das purinas absorvidas no intestino delgado e, as purinas endógenas, do metabolismo dos ácidos nucléicos (Chen \& Gomes, 1995).

A creatinina é formada no tecido muscular a partir da remoção irreversível e não enzimática de água, do fosfato creatinina, originada pelo metabolismo dos aminoácidos (González et al., 2000) e a excreção de creatinina, segundo a literatura é uma função constante do peso vivo dos animais (Valadares et al., 1999, Ørskov \& McDonald, 1979, Rennó et al., 2000).

Neste contexto, torna-se possível utilizar a creatinina para estimar o volume urinário, permitindo estimar a excreção de derivados de purinas e outros compostos sem a necessidade de coleta total de urina (Oliveira et al., 2001).

A excreção de derivados de purinas pelos ruminantes pode usada para estimar o fluxo intestinal de proteína microbiana, uma vez que a excreção endógena de derivados de purinas e absorção de purinas tenha sido previamente determinada (Chen \& Gomes, 1995). Segundo os mesmos autores, há diferenças no metabolismo de purinas, sendo já estabelecido que Bos taurus difere quanto ao nível de excreção endógena de purinas e a habilidade de utilização de purinas de origem exógena.

As purinas são prontamente absorvidas como nucleosídeos e bases livres no lúmen do intestino delgado e estão sujeitas a degradação extensiva por enzimas específicas como, guanina deaminase, adenosina deaminase e xantina oxidase, em sua passagem através da mucosa intestinal. É importante salientar que a extensão desta degradação determina a possibilidade metabólica das purinas a serem utilizadas pelos animais (Stangassinger et al., 1995).

Têm-se por intermédio da ação da enzimachave na degradação das purinas, a xantina oxidase, a conversão da hipoxantina em xantona e ácido úrico, este então é degradado a alantoína pela ação da uricase.

Existe pouca informação sobre derivados de purinas em gado zebu (Bos indicus). Embora seja improvável relatam que estes animais não tenham uricase no fígado, porém outras enzimas, como a xantina oxidase estão presentes no tecido hepático destes.

$\mathrm{Na}$ urina de bovinos, ambas as purinas endógenas e exógenas têm composição semelhante, de aproximadamente, $85 \%$ de alantoína e $15 \%$ de ácido úrico, xantina e hipoxantina não estão presentes em quantidades significativas nos bovinos (Chen \& Gomes, 1995).

Moscardini et al. (1998) utilizaram somente excreção de alantoína e ácido úrico para representar o total de excreção urinária de derivados de purinas. Liang et al. (1994) determinaram além dos derivados de purinas, também xantina e hipoxantina. A maioria dos estudos não utilizou determinação de xantina e hipoxantina para bovinos, pois nesta espécie verifica-se alta atividade da enzima xantina 
oxidase na conversão de xantina e hipoxantina em ácido úrico (Chen \& Gomes, 1995).

A estimativa do fluxo de proteína microbiana no duodeno, a partir dos derivados de purinas na urina necessita do conhecimento da relação $\mathrm{N}$ purina: $\mathrm{N}$ total dos microrganismos ruminais que é bastante variável (Vagnoni et al., 1997). Chen \& Gomes (1995) utilizaram relação igual a 0,116, a partir de dados da literatura. Valadares et al. (1997) relataram valores médios de 0,176. Dias (1999), Cardoso (1999), Tibo (1999), Ribeiro (1999) obtiveram relações de 0,$113 ; 0,104$; 0,$069 ; 0,143$, respectivamente.

As disponibilidades de energia e $\mathrm{N}$ no rúmen são os fatores nutricionais que mais limitam o crescimento microbiano (Berchielli et al., 2011, Van Soest, 1994). Estes autores verificaram que a alteração da razão volumoso e concentrado na dieta poderia influir no crescimento microbiano, em relação à variação na disponibilidade de energia.

A energia para a síntese de proteína microbiana é oriunda principalmente dos $\mathrm{CHO}$ dietéticos, cuja fonte pode afetar o crescimento microbiano. Se os carboidratos não estruturais (CNE) estiverem em alta proporção na ração e $\mathrm{pH}$ for mantido, os microrganismos fermentadores deste substrato vão crescer rapidamente resultando em maior crescimento microbiano; porém se houver acúmulo de ácido lático, o pH diminuirá e consequentemente ocorrerá redução da microbiota ruminal, diminuindo o consumo de matéria seca (Sniffen \& Robinson, 1987). Taxas mais rápidas de crescimento, associadas à passagem mais rápida de microrganismos para o intestino delgado podem reduzir a reciclagem de energia e $\mathrm{N}$ no rúmen, decorrente no decréscimo na lise das células, diminuindo assim os requisitos de mantença dos microrganismos, fornecendo assim maior quantidade de nutrientes para $o$ crescimento microbiano (Berchielli et al., 2011).

Segundo Russell et al. (1992) a melhor forma de expressar a eficiência microbiana seria em relação aos CHODR, em comparação com a MODR e o NDT, pois os carboidratos constituem a maior fonte de energia para os microrganismos ruminais quando comparados com os lipídeos e proteína bruta. Embora essa última possa contribuir como fonte energética, via fermentação dos esqueletos de carbono, derivados da deaminação de aminoácidos, esta não é sua principal função no rúmen.

O objetivo do presente estudo foi avaliar os efeitos da utilização da cana de açúcar suplementada a níveis crescentes de fontes de nitrogênio não protéico sobre a produção de proteína microbiana e excreções de derivados de purinas em vacas Holandesa $\mathrm{x}$ Zebu.

\section{Material e Métodos}

A pesquisa foi realizada na Fazenda Professor Hélio Barbosa localizada no município de Igarapé de propriedade da Escola de Veterinária da Universidade Federal de Minas Gerais UFMG. As análises laboratoriais foram realizadas no Laboratório de Nutrição Animal da Escola de Veterinária da Universidade Federal de Minas Gerais. O experimento teve duração de 84 dias sendo quatro períodos de 21 dias cada com 14 dias para adaptação as dietas e sete dias para coleta de dados. Foram utilizadas sete vacas Holandesa vs. Zebu, multíparas com $580 \mathrm{~kg}$ de peso vivo, $25 \mathrm{~kg}$ de leite por dia e 45 dias em lactação mantidas em sistema tipo tiestall com bebedouros e cochos de alimentação individual.

As dietas experimentais tiveram cana de açúcar, como única fonte de volumoso e inclusão de ureia tradicional ou ureia protegida (OptgenII $\left.{ }^{\circledR}\right)$, conforme Tabela 1. O OptgenII ${ }^{\circledR}$ (Alltech, Inc., Lexington, KY) é a ureia $(43 \% \mathrm{~N}$ ) na forma peletizada recoberta por um polímero biodegradável, capaz de controlar a liberação de amônia para o rúmen. Foram utilizadas duas fontes de NNP (ureia e OptigenII ${ }^{\circledR}$ ), acrescidos na cana de açúcar em três níveis $(0,3 ; 0,6$ e $0,9 \%$ - na matéria natural) com razão volumoso e concentrado de 50 e $50 \%$ e uma dieta controle sem fonte de nitrogênio não protéico, conforme apresentado na Tabela 1. Cada uma das sete vacas recebeu uma sequência de quatro tratamentos referente a cada período experimental de 21 dias de duração, sendo 14 dias de adaptação e sete dias de coleta de urina.

As coletas de urina foram realizadas duas vezes ao dia, sempre três horas após o primeiro e segundo arraçoamento compondo uma amostra spot de cada animal. Alíquotas de $10 \mathrm{~mL}$ de urina, foram diluídas em $40 \mathrm{~mL}$ de ácido sulfúrico a $0,036 \mathrm{~N}$ e congeladas a $-20^{\circ} \mathrm{C}$ para análise de determinação dos derivados de purina (ácido úrico e alantoína) e creatinina conforme descrito por Valadares et al. (1997). 
Tabela 1. Composição dos ingredientes das dietas (kg de MS) e da concentração de nutrientes na MS (\%)

\begin{tabular}{llllllll}
\hline \multirow{2}{*}{ Item } & \multicolumn{7}{c}{ Tratamentos $^{2}$} \\
\cline { 2 - 8 } & $\mathrm{C}$ & $0,3 \mathrm{U}$ & $0,6 \mathrm{U}$ & $0,9 \mathrm{U}$ & $0,3 \mathrm{OP}$ & $0,6 \mathrm{OP}$ & $0,9 \mathrm{OP}$ \\
\hline Cana de açúcar & 10,0 & 10,0 & 10,0 & 10,0 & 10,0 & 10,0 & 10,0 \\
Torta de algodão & 1,60 & 1,64 & 1,18 & 0,72 & 1,59 & 1,11 & 1,01 \\
Milho fubá & 2,00 & 2,57 & 3,32 & 4,08 & 2,52 & 3,23 & 3,79 \\
Farelo de soja & 4,20 & 3,50 & 3,10 & 2,70 & 3,58 & 3,26 & 2,70 \\
Ureia & - & 0,10 & 0,20 & 0,30 & - & - & - \\
Optigen ${ }^{\circledR}$ & - & - & - & - & 0,10 & 0,20 & 0,30 \\
Soynúcleo & 0,62 & 0,62 & 0,62 & 0,62 & 0,62 & 0,62 & 0,62 \\
Calcário calcítico & 0,05 & 0,05 & 0,05 & 0,05 & 0,05 & 0,05 & 0,05 \\
Total & 18,57 & 18,57 & 18,57 & 18,57 & 18,57 & 18,57 & 18,57 \\
\hline
\end{tabular}

${ }^{1}$ Suplemento mineral, vitamínico com leveduras e lasalocida: $13,5 \% \mathrm{Ca} ; 5,0 \% \mathrm{P} ; 2,9 \% \mathrm{Mg} ; 4,7 \% \mathrm{~K} ; 9,3 \% \mathrm{Na}$; 4,0\% S; 5,3 ppm Co; 300 ppm Cu; 650 ppm Fe; 25,6 ppm I; 1.530 ppm Mn; 12 ppm Se; 2.040 ppm Zn; 165.000 UI Vitamina A; 50.000 UI Vitamina D; 1.000 UI Vitamina E; 28 ppm Biotina; 430 ppm Lasalocida; $2,1 \times 10^{11}$ UFC Levedura. ${ }^{2}$ Tratamentos $=\mathrm{C}=$ controle; $0,3 \mathrm{U}=0,3 \%$ ureia; $0,6 \mathrm{U}=0,6 \%$ ureia; $0,9 \mathrm{U}=0,9 \%$ ureia; $0, \mathrm{OP}=$ $0,3 \%$ OptgenII ${ }^{\circledR} ; 0,6 \mathrm{OP}=0,6 \%$ OptgenII ${ }^{\circledR} ; 0,9 \mathrm{OP}=0,9 \% \mathrm{OptgenII}^{\circledR}$. Fórmula estimada pelo software Spartan.

A creatinina e ácido úrico foram determinados na urina diluída, utilizando-se kits comerciais (Labtest Diagnóstica S. A). A análise de alantoína na urina spot foi realizada pelo método colorimétrico, conforme descrito por Chen \& Gomes (1995). As purinas absorvidas (X $\mathrm{mmol} / \mathrm{dia}$ ) foram estimadas a partir da excreção de derivados de purinas ( $\mathrm{Y} \mathrm{mmol} / \mathrm{dia}$ ) por meio da equação $\mathrm{Y}=0,85 \mathrm{X}+0,385 \mathrm{PC}^{0,75}$, onde, 0,85 é a recuperação das purinas absorvidas como derivados de purina e, $0,385 \mathrm{PC}^{0,75}$, é a contribuição endógena para excreção de purinas (Verbic et al., 1990). A síntese ruminal de compostos nitrogenados (Y, g N/dia) foi calculada com base nas purinas absorvidas (X $\mathrm{mmol} /$ dia) utilizando a seguinte equação: $\mathrm{Y}=70$ $\mathrm{X} /(0,83 \times 0,134 \times 1000)$, em que 70 , é o conteúdo de $\mathrm{N}$ nas purinas $(\mathrm{mgN} / \mathrm{mmol}), 0,134$ a razão de $\mathrm{N}-$ Purina/ $\mathrm{N}$ total nas bactérias, e, 0,83 é a digestibilidade das purinas microbianas (Valadares et al., 1999).

\section{Determinando a alantoína}

Princípio: A alantoína é submetida a hidrólise alcalina a $100^{\circ} \mathrm{C}$, resultando em ácido alantóico,que é degradado a uréia e ácido glioxílico em solução ácida. Porém, o ácido glioxílico reage com cloreto de Fenilhidrazina para produzir uma Fenilhidrazina do ácido. $\mathrm{O}$ produto forma um cromógeno instável com ferricianeto de potássio e a cor é lida a 552 namômetros (nm) de absorbância.

\section{Reagentes e equipamentos}

1. Espectrofotômetro.

2. Hidróxido de sódio $(\mathrm{NaOH} 0,5 \mathrm{M})$ sendo 50 $\mathrm{ml}$ para 10 amostras e duplicata.Pesar $1 \mathrm{~g}=$ $0,5 \mathrm{M}$.

3. $\mathrm{NaOH}$ a $0,01 \mathrm{M}(100 \mathrm{ml})$ para 10 amostras.Pesar 0,04 g=0,01 M.

4. Ácido Clorídrico (HCL a 0,5 M), $50 \mathrm{ml}$ para 10 amostras.

5. Cloreto de Fenilhidrazina0,023 M(preparar no momento da análise).

6. Ferricianeto de potássio a $0,05 \mathrm{M}$ (preparar no momento da análise).

7. HCL concentrado $(11,4 \mathrm{~N})$ resfriado a ($20^{\circ} \mathrm{C}$ ) pelo menos 20 minutos antes da análise (150 $\mathrm{ml}$ para 10 amostras).

8. Banho de álcool, $40 \% \mathrm{v} / \mathrm{v}$ mantido a $\left(-20^{\circ}\right.$ C).

9. Alantoína.

\section{Preparo das soluções}

Solução stock de alantoína

1. Pesar $50 \mathrm{mg}$ de alantoína e dissolver a alantoína em $100 \mathrm{ml}$ de $\mathrm{NaOH}$ a 0,01 M (a adição de $\mathrm{NaOH}$ é apenas para ajudar a dissolver a alantoína).

2. Transferir para um balão volumétrico de $500 \mathrm{ml}$.

3. Completar o volume para $500 \mathrm{ml}$ com água destilada. 
Solução padrão de alantoína

Para preparar $50 \mathrm{ml}$ de solução padrão de alantoína de 10, 20, 30, 40, 50 e $60 \mathrm{mg} / \mathrm{L}$, colocar $5,10,15,20,25,30 \mathrm{ml}$ da solução stock de alantoína em balões volumétricos de $50 \mathrm{ml}$ e completar o volume até o menisco com água destilada.

Soluções de cloreto de fenilhidrazina e ferricianeto de potássio

1. Devem ser preparadas no dia da análise.

2. Manter em geladeira antes do uso.

3. $50 \mathrm{ml}$ é o bastante para 10 amostras em duplicata.

4. Pesar 0,1663 g de cloreto de fenilhidrazina.

5. Dissolver em um béquer e transferir para um balão volumétrico de $50 \mathrm{ml}$, completar o volume com água destilada até o menisco.

6. Pesar $0,835 \mathrm{~g}$ de ferricianeto de potássio e transferir para um balão volumétrico de 50 ml,dissolver e completar o volume com água destilada até o menisco.

7. Procurar trabalhar com tubos de $20 \mathrm{ml}$.

\section{Procedimento Alantoína (Tabela 2)}

1. Misturar bem o conteúdo dos tubos de ensaio em vórtex.

2. Colocar em banho - maria a $1000 \mathrm{C}$ ou fervendo por 7 minutos.

3. Resfriar os tubos em água gelada.

4. Seguir na coluna da tabela $2(1 \mathrm{ml}$ em todos os tubos)

5. Misturar e colocar em banho-maria a 1000 $\mathrm{C}$ ou fervendo por 7 minutos

6. Colocar imediatamente em banho com gelo (50\% de água+ $50 \%$ de álcool mantidos em congelador) mínimo de 2 litros por 5 minutos.

7. Seguir na coluna da tabela $1(1 \mathrm{ml}$ em todos os tubos).

8. Vedar os tubos tubos com papel filme e misturar manualmente virando de um lado para o outro 4 vezes e fazer a leitura em espectrofotômetro a $522 \mathrm{~nm}$ de absorbância ( $\mathrm{DO}=$ densidade óptica).

9. Seguir na coluna da tabela $2(3 \mathrm{ml}$ em todos os tubos)

Tabela 2. Procedimento (Alantoína)

\begin{tabular}{|c|c|c|c|c|c|c|c|c|}
\hline \multirow[t]{2}{*}{ Amostra } & & \multicolumn{6}{|c|}{ Padrão } & \multirow[t]{2}{*}{$\overline{\text { Branco }}$} \\
\hline & & 10 & 20 & 30 & 40 & 50 & 60 & \\
\hline Amostra & $1 \mathrm{ml}$ & & & & & & & \\
\hline Água destiladada & & & & & & & & $1 \mathrm{ml}$ \\
\hline Padrão 10 mg/l & & $1 \mathrm{ml}$ & & & & & & \\
\hline Padrão 20 mg/l & & & $1 \mathrm{ml}$ & & & & & \\
\hline Padrão 30 mg/l & - & & & $1 \mathrm{ml}$ & & & & \\
\hline Padrão 40 mg/l & & & & & $1 \mathrm{ml}$ & & & \\
\hline Padrão50 mg/l & & & & & & $1 \mathrm{ml}$ & & \\
\hline Padrão60 mg/l & & & & & & & $1 \mathrm{mg}$ & \\
\hline Água destilada & $5 \mathrm{ml}$ & $5 \mathrm{ml}$ & $5 \mathrm{ml}$ & $5 \mathrm{ml}$ & $5 \mathrm{ml}$ & $5 \mathrm{ml}$ & $5 \mathrm{ml}$ & $5 \mathrm{ml}$ \\
\hline $\mathrm{NaOH} 0,5 \mathrm{M}$ & $1 \mathrm{ml}$ & $1 \mathrm{ml}$ & $1 \mathrm{ml}$ & $1 \mathrm{ml}$ & $1 \mathrm{ml}$ & $1 \mathrm{ml}$ & $1 \mathrm{ml}$ & $1 \mathrm{ml}$ \\
\hline HCL $0,5 \mathrm{M}$ & $1 \mathrm{ml}$ & $1 \mathrm{ml}$ & $1 \mathrm{ml}$ & $1 \mathrm{ml}$ & $1 \mathrm{ml}$ & $1 \mathrm{ml}$ & $1 \mathrm{ml}$ & $1 \mathrm{ml}$ \\
\hline HCL concentrado & $3 \mathrm{ml}$ & $3 \mathrm{ml}$ & $3 \mathrm{ml}$ & $3 \mathrm{ml}$ & $3 \mathrm{ml}$ & $3 \mathrm{ml}$ & $3 \mathrm{ml}$ & $3 \mathrm{ml}$ \\
\hline Ferricianeto & $1 \mathrm{ml}$ & $1 \mathrm{ml}$ & $1 \mathrm{ml}$ & $1 \mathrm{ml}$ & $1 \mathrm{ml}$ & $1 \mathrm{ml}$ & $1 \mathrm{ml}$ & $1 \mathrm{ml}$ \\
\hline
\end{tabular}

Observação: Antes de iniciar as análises prepara toda a bancada, ligar o espectro pelo menos 30 minutos antes da leitura para estabilizar o mesmo. Os cálculos para alantoína são realizados por equações de regressão (excel). A cor da amostra é estável por 15 minutos, então trabalhar com uma quantidade que possa ser lida durante este período.

Exemplo de diluições:

Urina $=1: 10\left(5 \mathrm{ml}\right.$ de urina $+45 \mathrm{ml} \mathrm{de} \mathrm{H}_{2} \mathrm{SO}_{4}$ a $\left.0,036 \mathrm{~N}\right)$ esta é feita no momento da coleta nos frascos que ficarão guardados. Deverá ser feita em outros tubos com a numeração utilizada para identificar os mesmos de acordo com os animais, e somente aí que utilizará $1 \mathrm{ml}$ da mesma nos tubos onde será feito o procedimento de análise (aquele $1 \mathrm{ml}$ da amostra da Tabela 2).

Alantoína deve ser 1:100. Então é só diluir a amostra da fazenda em ( $0,5 \mathrm{ml}$ de urina do frasco $+4,5 \mathrm{ml}$ de água destilada) fazer em tubos de ensaio de $20 \mathrm{ml}$ sempre indicando no tubo o número do animal que se refere a amostra. Esta diluição é feita em tubos separados, somente após esta diluição que utilizará $1 \mathrm{ml}$ da solução nos tubos onde será feita as análises (aquele $1 \mathrm{ml}$ de amostra da tabela 2).

\section{Creatinina}

Fazer a diluição da amostra pipetando $1 \mathrm{ml}$ de amostra $+1,5 \mathrm{ml}$ de água destilada em um béquer de $50 \mathrm{ml}$. Trabalhar com tubos de ensaio de 10 ml e misturar o conteúdo destes usando o vortex. 


\section{Procedimento creatinina (Tabela 3 )}

Na fazenda a urina está diluída em 1:10, porém no laboratório, é preciso diluí-la para 1:25, ou seja, $1 \mathrm{ml}$ de urina (diluída na fazenda) $+1,5$ $\mathrm{ml}$ de água destilada. Multiplicar o resultado da análise por 25 .

Depois de realizado o procedimento identificado na Tabela 3 , com as devidas diluições, fazer a mistura e incubar as amostras em banho-maria a $37^{\circ} \mathrm{C}$ por 10 minutos. O nível de água do banho-maria deve ser superior ao dos reagentes dos tubos de ensaio. Determinar a absorbância $(\mathrm{DO}=510 \mathrm{~nm})$.

Logo após a primeira leitura, colocar acidificante número 4 conforme identificado na Tabela 4.

Misturar em vórtex e fazer a leitura $(\mathrm{DO}=510$ $\mathrm{nm})$.

Cálculos creatinina:

Creatinina $(\mathrm{MG} / \mathrm{dl})=\mathrm{A} 1-\mathrm{A} 2 /$ Absorbância do padrão 4 A1 e A2 são as amostras teste a serem analisadas ( $\mathrm{A} 1=$ amostra 1 e $\mathrm{A} 2$ repetição de $\mathrm{A} 1)$.

Tabela 3. Procedimento creatinina

\begin{tabular}{|c|c|c|c|}
\hline & Branco & Amostra & Padrão \\
\hline $\begin{array}{l}\text { Tampão } \\
\text { Numero } 2\end{array}$ & $2,0 \mathrm{ml}$ & $2,0 \mathrm{ml}$ & $2,0 \mathrm{ml}$ \\
\hline Amostra & ------ & $0,25 \mathrm{ml}$ & - \\
\hline $\begin{array}{l}\text { Água } \\
\text { Destilada }\end{array}$ & $0,25 \mathrm{ml}$ & - & - \\
\hline Padrão (3) & - & - & $0,25 \mathrm{ml}$ \\
\hline $\begin{array}{l}\text { Ácidopícrico } \\
\text { (1) }\end{array}$ & $0,5 \mathrm{ml}$ & $0,5 \mathrm{ml}$ & $0,5 \mathrm{ml}$ \\
\hline
\end{tabular}

Os números entre parênteses indicam o número do reagente

Tabela 4. Adição do acidificante nos tubos.

\begin{tabular}{cccc}
\hline & Branco & Amostra & Padrão \\
\hline $\begin{array}{c}\text { Acidificante } \\
(4)\end{array}$ & $0,1 \mathrm{ml}$ & $0,1 \mathrm{ml}$ & - \\
\hline Os & & & \\
\hline
\end{tabular}

Os números entre parênteses indicam o número do reagente

\section{Ácido úrico}

1. Pipetar $10 \mathrm{ml}$ da amostra de urina do frasco (fazenda) e transferir para um béquer de 50 $\mathrm{ml}$ e fazer a correção do $\mathrm{pH}$ utilizando $\mathrm{NaOH}$ a 5\% (pesar 2,5 gramas para $50 \mathrm{ml}$ ) onde o $\mathrm{pH}$ da amostra deverá ficar entre 7,0 a 9,0 .

2. Colocaras amostras em banho-maria a $57^{\circ} \mathrm{C}$ por 10 minutos.
3. Tomar 3 tubos de ensaio com as repetições para cada item abaixo e proceder como segue (Tabela 5):

4. Misturar em vortex e incubar em banhomaria a $37^{\circ} \mathrm{C}$ durante 10 minutos. O nível de água do banho-maria deve estar acima do nível dos reagentes dos tubos de ensaio

5. Determinar a absorbância $(\mathrm{DO}=520 \mathrm{~nm})$.

Tabela 5. Procedimento ácido úrico

\begin{tabular}{lccc}
\hline & Branco & Amostra & Padrão \\
\hline Amostra & - & $\begin{array}{c}20 \\
\text { microlitros }\end{array}$ & - \\
Padrão(3) & - & - & 20 \\
$\begin{array}{l}\text { Reagente de } \\
\text { trabalho }\end{array}$ & $1,0 \mathrm{ml}$ & $1,0 \mathrm{ml}$ & $1,0 \mathrm{ml}$ \\
\hline
\end{tabular}

Observação: a cor do material é estável por 15 minutos, então a leitura dever ser realizada o mais rápido possível. A quantidade mínima para leitura dependerá do tamanho da cubeta que será utilizada.

Exemplo: cubeta de $1 \mathrm{ml}$ ou de $2 \mathrm{ml}$, antes de tudo deverá descongelar as amostras sem utilizar de meios artificiais (aquecimento a fogo).

Cálculos: ácido úrico $(\mathrm{MG} / \mathrm{dl})=$ Absorbância do teste/absorbância do padrão.

As análises estatísticas foram realizadas aplicando-se o teste de Tukey com probabilidade de 5\%, utilizando o procedimento MIXED do SAS (2004). As médias obtidas para as variáveis dependentes foram ajustadas segundo o modelo matemático proposto:

$\mathrm{Y}_{\mathrm{ijk}}=\mu+\mathrm{T}_{\mathrm{i}}+\mathrm{B}_{\mathrm{j}}+\mathrm{P}_{\mathrm{k}}+\mathrm{e}_{\mathrm{ijk}}$, onde

$Y_{\mathrm{ijk}}=$ observação do tratamento $\mathrm{i}$, no bloco $\mathrm{j}$, no período k;

$\mu=$ média geral;

$\mathrm{T}_{\mathrm{i}}=$ efeito do tratamento $\mathrm{i}(\mathrm{T}=1,2 \ldots, 7)$;

$\mathrm{B}_{\mathrm{j}}=$ efeito do bloco $\mathrm{j}(\mathrm{J}=1,2 \ldots, 7)$;

$\mathrm{P}_{\mathrm{k}}=$ efeito do período $\mathrm{k}(\mathrm{P}=1,2,3,4)$;

$\mathrm{e}_{\mathrm{ijk}}=$ variação aleatória atribuída ao tratamento $\mathrm{i}$, na vaca $\mathrm{j}$, no período

\section{Resultados e Discussão}

Conforme observado na Tabela 6, houve efeito $(\mathrm{P}<0,05)$ apenas para excreção de alantoína; sendo superior em média $51 \%$ em relação aos tratamentos $\mathrm{C}, 0,3 \mathrm{U}, 0,6 \mathrm{U}$ e $0,9 \mathrm{OP}$, respectivamente. Estes valores, estão próximos aos observados por Valadares et al. (1999) com valores obtidos para vacas de alta produção (40 $\mathrm{kg} / \mathrm{dia}$ ) de 369 a $535 \mathrm{mmol} / \mathrm{dia}$ de alantoína. 
Já Oliveira et al. (2001) trabalhando com doses crescentes de ureia na dieta de vacas observaram efeito quadrático nas excreções diárias de alantoína para vacas em lactação obtendo valores máximos de 258 e $297 \mathrm{mmol} / \mathrm{dia}$ para as doses de 5,30 e 4,75\% de $\mathrm{N}$ na dieta respectivamente.

Não houve efeito para os volumes urinários estimados $(\mathrm{P}>0,05)$. Estes dados estão de acordo com Valadares et al. (1999) que, também não verificaram diferenças entre volumes urinários estimados e os obtidos em coleta total, para dietas com teores de 25,50 e $65 \%$ de concentrado, e que também, não verificaram efeito nas excreções diárias de derivados de purinas totais. Estes dados reforçam que a metodologia de determinação dos derivados de purinas em coletas de urina spot, é adequada e, pode substituir a coleta total de urina.

Tabela 6- Volume urinário (VUR, L/dia), Alantoína (ALA, mmol/dia), Ácido úrico (AcU, mmol/dia), creatinina (CRE, mmol/dia), Purinas totais (Pur Totais mmol/dia), Purinas absorvidas (Pabs, mmol/dia), nitrogênio microbiano (Nmic, g/dia) e proteína microbiana (Pmic, g/dia) em vacas leiteiras alimentadas com cana de açúcar e suplementadas por fontes de nitrogênio não protéico de diferentes degradabilidades ruminais.

\begin{tabular}{lccccccccc}
\hline \multirow{2}{*}{ Item } & \multicolumn{10}{c}{ Tratamentos $^{2}$} \\
\cline { 2 - 10 } & $\mathrm{C}$ & $0,3 \mathrm{U}$ & $0,6 \mathrm{U}$ & $0,9 \mathrm{U}$ & $0,3 \mathrm{OP}$ & $0,6 \mathrm{OP}$ & 0,9 OP & EPM & $P$ \\
\hline VUR, L/dia & 47,21 & 60,64 & 57,80 & 48,51 & 50,00 & 58,30 & 51,15 & 8,79 & 0,400 \\
ALA, mmol/dia & $309,94 \mathrm{~b}$ & $318,21 \mathrm{~b}$ & $396,85 \mathrm{~b}$ & $616,42 \mathrm{a}$ & $519,41 \mathrm{a}$ & $573,95 \mathrm{a}$ & $384,05 \mathrm{~b}$ & 51,32 & 0,001 \\
AcU, mmol/dia & 104,51 & 143,98 & 89,95 & 130,82 & 104,41 & 114,82 & 115,35 & 24,75 & 0,510 \\
CRE, mmol/dia & 33,10 & 33,50 & 29,93 & 53,27 & 35,47 & 47,05 & 39,18 & 9,48 & 0,445 \\
Pur Totais, mmol/dia & 414,45 & 788,00 & 494,83 & 749,00 & 563,82 & 671,33 & 499,40 & 116,77 & 0,112 \\
Pabs, mmol/dia & 460,39 & 929,46 & 556,00 & 857,16 & 591,35 & 821,34 & 562,49 & 137,68 & 0,130 \\
Nmic, g/dia & 334,70 & 594,47 & 407,71 & 623,16 & 474,10 & 597,42 & 481,39 & 103,48 & 0,374 \\
Pmic, g/dia & 2204,36 & 3854,82 & 2528,52 & 3894,90 & 2686,87 & 3593,59 & 2555,82 & 630,53 & 0,250 \\
\hline
\end{tabular}

${ }^{2} \mathrm{C}=$ controle, $0,3 \mathrm{U}=0,3 \%$ de ureia, $0,6 \mathrm{U}=0,6 \%$ de ureia, $0,9 \mathrm{U}=0,9 \%$ de ureia, $\mathrm{T} 4=0,3 \%$ de OptigenII ${ }^{\circledR}, \mathrm{T} 5=$ $0,6 \%$ de OptigenII ${ }^{\circledR}, \mathrm{T} 6=0,9 \%$ de OptigenII ${ }^{\circledR}$.

A excreção diária de ácido úrico não foi influenciada $(\mathrm{P}>0,05)$ pelos teores ou fontes de NNP na dieta. Mesmo sem efeito estatístico, observa-se que no tratamento $0,6 \mathrm{U}$ a excreção de ácido úrico foi $14,0 \%, 37,5 \%, 31,0 \%, 22,0 \mathrm{e}$ $23,0 \%$ inferior em relação aos tratamentos $\mathrm{C}$ e 0,3OP; $0,3 \mathrm{U} ; \quad 0,9 \mathrm{U} ; \quad 0,6 \mathrm{OP} \quad$ e, $0,9 \mathrm{OP}$, respectivamente. Neste contexto, uma vez que seu produto principal de excreção é ureia pode-se inferir que o tratamento $0,6 \mathrm{U}$ foi mais eficiente na utilização deste composto em relação aos demais tratamentos (Lehninger, 2008).

Pode-se verificar para o tratamento 0,6U, redução nas concentrações de todas as demais variáveis estudadas, o que causou redução na produção de N microbiano (g/dia) e consequentemente na produção de proteína microbiana $(\mathrm{g} / \mathrm{dia})$, o que também pode ser observado para o tratamento controle (C).

A ausência de efeito para o volume urinário (VUR, L/dia) pode ser explicado pela adequação protéica das dietas, em que as mesmas foram isonitrogenadas, uma vez que níveis crescentes de proteína não degradável no rúmen (PNDR) de vacas lactantes afetam linearmente o volume urinário (Moscardini et al., 1998).

Maior produção de nitrogênio microbiano (g/dia) e proteína microbiana podem ser observadas para os tratamentos $0,3 \mathrm{U} ; 0,9 \mathrm{U}$ e $0,6 \mathrm{OP}$, com média de $3781 \mathrm{~g} / \mathrm{dia}$, enquanto que para os demais tratamentos, a média obtida foi de $2494 \mathrm{~g}$ de proteína microbiana por dia, uma diferença de $66 \%$ a menos. De acordo com esses dados, observa-se uma drástica redução na produção microbiana para tais tratamentos, o que poderá acarretar perdas econômicas, devido ao desperdício de energia e, em consequência, redução do desempenho do animal causado pela redução na síntese microbiana.

Sendo assim, de acordo com NRC (2001), se considerarmos que a Pmic contém 80,0\% de proteína verdadeira, os tratamentos $0,3 \mathrm{U} ; 0,9 \mathrm{U}$ e, 0,6OP, com média de $3781 \mathrm{~g} / \mathrm{dia}$, representa $3025,00 \mathrm{~g}$ de proteína verdadeira e que esta quantidade seria suficiente para maximizar $o$ 
desempenho produtivo dos animais utilizados no presente estudo.

\section{Conclusões}

Para vacas com produções diárias de leite de $25,0 \mathrm{~kg}$ por dia pode-se utilizar diferentes fontes de nitrogênio não protéico na dieta, de liberação controlada ou não, pois os mesmos não alteram estatisticamente a produção de proteína microbiana, porém, em relação ao preço destes compostos no mercado e, visando maximizar o desempenho dos animais através da otimização da produção de proteína microbiana, principalmente no que diz respeito ao perfil de aminoácidos limitantes nesses microrganismos (97\% de metionina e $100 \%$ de lisina) a melhor dose utilizada no presente estudo foi a $0,3 \%$ de ureia.

\section{Agradecimentos}

A todos que de forma direta ou indireta participaram deste trabalho. A CAPES pela concessão da bolsa de estudos.

\section{Referências Bibliográficas}

Berchielli, T. T., Pires, A. V. \& Oliveira, S. G. (2011). Nutrição de Ruminantes. 2th ed. FUNEP, Jaboticabal, Brazil.

Chen, X. \& Ørskov, E. (2004). Research on urinary excretion of purine derivatives in ruminants: past, present and future. Estimation of microbial protein supply in ruminants using urinary purine derivatives. Springer.

Chen, X. B. \& Gomes, M. J. (1995). Estimation of microbial protein supply to sheep and cattle based on urinary excretion of purine derivatives-an overview of the technical details. International Feed Resources Unit.

Costa, L. T., Silva, F. F., Veloso, C. M., Pires, A. J. V., Rocha Neto, A. L., Bonomo, P., Mendes, F. B. L., Oliveira, J. S., Azevêdo, S. T. \& Silva, V. L. (2011). Comportamento ingestivo de vacas alimentadas com cana de açúcar e diferentes níveis de concentrado. Archivos de Zootecnia, 60, 265-273.
Costa, M. G., Campos, J. M. S., Valadares Filho, S. C., Valadares, R. F. D., Mendonça, S. S., Souza, D. P. \& Teixeira, M. P. (2005). Desempenho produtivo de vacas leiteiras alimentadas com diferentes proporções de cana de açúcar e concentrado ou silagem de milho na dieta. Revista Brasileira de Zootecnia, 34, 24372445.

González, F. H. D., Conceição, T. R., Siqueira, A. J. S. \& La Rosa, V. L. (2000). Variações sangüíneas de uréia, creatinina, albumina e fósforo em bovinos de corte no Rio Grande do Sul. A Hora Veterinária, 20, 59-62.

Liang, J., Matsumoto, M. \& Young, B. (1994). Purine derivative excretion and ruminal microbial yield in Malaysian cattle and swamp buffalo. Animal Feed Science and Technology, 47, 189-199.

Maeda, E. M., Zeoula, L. M., Jobim, C. C., Bertaglia, F., Jonker, R. C., Geron, L. J. V. \& Henrique, D. S. (2011). Chemical composition, fermentation, in vitro digestibility and in situ degradability of sugar cane silages with Lactobacillus, urea and agricultural byproduct. Revista Brasileira de Zootecnia, 40, 2866-2877.

Moscardini, S., Wright, T. C., Luimes, P. H., McBride, B. W. \& Susmel, P. (1998). Effects of rumen-undegradable protein and feed intake on purine derivative and urea nitrogen: Comparison with predictions from the Cornell Net Carbohydrate and Protein System. Journal of Dairy Science, 81, 2421-2429.

NRC. (2000). Nutrient Requirements of Beef Cattle, 7th rev. edn. Natl. Acad. Press, Washington, DC, USA.

NRC. (2001). Nutrient Requirements of Dairy Cattle, 7th rev. edn. Natl. Acad. Press, Washington, DC.

Oliveira, A. S., Valadares, R. F. D., Valadares Filho, S. C., Cecon, P. R., Rennó, L. N., Queiroz, A. C. \& Chizzotti, M. L. (2001). Produção de proteína microbiana e estimativas das excreções de 
derivados de purinas e de uréia em vacas lactantes alimentadas com rações isoprotéicas contendo diferentes níveis de compostos nitrogenados não-protéicos. Revista Brasileira de Zootecnia, 30, 16211629.

Ørskov, E. R. \& McDonald, I. (1979). The estimation of protein degradability in the rumen from incubation measurements weighted according to rate of passage. The Journal of Agricultural Science, 92, 499503.

Rennó, L. N., Valadares, R. F. D., Leão, M. I. \& Valadares Filho, S. C. (2000). Estimativa da produção de proteína microbiana pelos derivados de purinas na urina em novilhos. Revista Brasileira de Zootecnia, 29, 1223-1234.

Russell, J. B., O'connor, J. D., Fox, D. G., Van Soest, P. J. \& Sniffen, C. J. (1992). A net carbohydrate and protein system for evaluating cattle diets: I. Ruminal fermentation. Journal of Animal Science, 70, 3551-3561.

SAS. 2004. SAS/STAT User guide, Version 9.1.2. SAS Institute Inc, Cary, NC, USA.

Sniffen, C. \& Robinson, P. (1987). Microbial growth and flow as influenced by dietary manipulations. Journal of Dairy Science, 70, 425-441.

Stangassinger, M., Chen, X., Lindberg, J., Giesecke, D., Engelhardt, W. v., Leonhard-Marek, S. \& Breves, G. (1995). Metabolism of purines in relation to microbial production. In: Engelhardt, W. V., Leonhard-Marek, S., Breve, G. \& Giesecke, D. (eds.) Ruminant physiology: digestion, metabolism, growth and reproduction. Proceedings 8th International Symposium on Ruminant Physiology. Delmar Publishers.
Vagnoni, D., Broderick, G., Clayton, M. \& Hatfield, R. (1997). Excretion of purine derivatives by Holstein cows abomasally infused with incremental amounts of purines. Journal of Dairy Science, 80, 1695-1702.

Valadares, R. F. D., Broderick, G. A., Valadares Filho, S. C. \& Clayton, M. K. (1999). Effect of replacing alfalfa silage with high moisture corn on ruminal protein synthesis estimated from excretion of total purine derivatives. Journal of Dairy Science, 82, 2686-2696.

Valadares, R. F. D., Gonçalves, L. C., Rodriguez, N., Valadares Filho, S. C. \& Sampaio, I. (1997). Níveis de proteína em dietas de bovinos. 4. Concentrações de amônia ruminal e uréia plasmática e excreções de uréia e creatinina. Revista Brasileira de Zootecnia, 26, 1270-1278.

Van Soest, P. J. (1994). Nutritional ecology of the ruminant. Cornell University Press, Ithaca, NY, USA.

Verbic, J., Chen, X., MacLeod, N. \& Ørskov, E. (1990). Excretion of purine derivatives by ruminants. Effect of microbial nucleic acid infusion on purine derivative excretion by steers. The Journal of Agricultural Science, 114, 243-248.

Recebido em Maio 5, 2015

Aceito em Setembro 24, 2015

License information: This is an open-access article distributed under the terms of the Creative Commons Attribution License, which permits unrestricted use, distribution, and reproduction in any medium, provided the original work is properly cited. 